\title{
COMPARATIVE METABOLISM OF BLASTOCYSTS, EXTRAEMBRYONIC MEMBRANES, AND UTERINE ENDOMETRIUM OF THE MOUSE ${ }^{1,2}$
}

\author{
RAYMOND ARTHUR POPP
}

Department of Zoology, University of Michigan, Ann Arbor, Michigan ${ }^{3}$

FOUR FIGURES

\section{INTRODUCTION}

An embryo is a resultant of many interacting sequential physical and chemical processes where each event is dependent upon others occurring either in neighboring or distant positions. In the mammalian embryo the harmonious interactions of the embryo, its extraembryonic membranes, and the uterine endometrium provide the appropriate conditions necessary for its development. The nature of some of these interrelated activities might be revealed by analyzing the cellular activities of each of these tissues at successive stages of embryonic development.

Several investigators have shown that mammalian embryos (rabbit-Heape, 1890; Brachet, '13; and Maximow, '23, '25; rat-Nicholas, '33, '42; and Nicholas and Rudnick, '33, '38; mouse-Bittner and Little, '37; Gluecksohn-Schoenheimer, '41, '44; Runner, '47 ; Fawcett et al., '47 ; Grobstein, '50; and

1 This investigation was supported in part by a Horace H. Rackham Graduate Student Research Grant No. 143. The author was the recipient of a Horace $H$. Rackham Predoctoral Fellowship during the final year of this study.

Based on part of a thesis submitted in partial fulfillment of the requirements for the degree of Doctor of Philosophy at the University of Michigan. I wish to express my appreciation for the consultation received from Dr. Clement L. Markert during the course of this investigation and the preparation of this manuseript.

s Present address: Biology Division, Oak Ridge National Laboratory, Oak Ridge, Tennessee. 
Whitten, '56) can be removed from oviducts and uteri without injury and, if placed in a suitable environment, will continue their normal development for variable periods of time. These experiments also demonstrated that some factors which stimulate embryonic growth in vivo were absent from the conditions of in vitro culture.

Rather specific interactions, which may be related to these growth-promoting factors, are known to exist between uteri and embryos. Results of interspecific embryonic transfers by Briones and Beatty ('54) indicate that young embryos are highly dependent upon the unique characteristics of the milieu in utero of their own species. This is discouraging since it would seem that the uterus of any rodent could provide better environmental conditions for the growth of fastidious blastocysts of another rodent than could any synthetic medium. Many experiments on the effects of various biochemical substances upon embryonic development in vivo and in vitro have been reviewed by Pincus and Werthessen ('38). Among these substances at least the sex hormones have been excluded as essential growth-stimulants. Indeed, Fawcett et al. ('47), and Runner ('47) found that the maternal environment is unessential for blastocyst development. The in vivo growthstimulants, although present in both males and females, remain unknown. A different experimental approach, based on an analysis of the metabolic activities of blastocysts, the extraembryonic membranes, and the uterine endometrium, perhaps could furnish new information concerning the nutritional needs of the developing embryo.

The recent advances in chromatography which make practical the separation and identification of large numbers of biological substances and the recent availability of radioisotopically labeled substrates with high specific activity make it possible now to study some aspects of the metabolic activities of mammalian blastocysts and of very small pieces of extraembryonic tissues to convert uniformly radioisotopically labeled glucose-C-14 (U-glucose-C-14) into other metabolites which then can be separated and identified chromatographi- 
cally. All metabolites containing C-14 must have derived at least a portion of their molecular structures from the U-glucose-C-14 substrate added to the medium in which the tissues were cultivated.

\section{MATERIALS AND METHODS}

The animals used in this investigation were highly inbred C57BL/6 mice raised in our laboratory or obtained from the Roscoe B. Jackson Memorial Laboratory in Bar Harbor, Maine. Breeding females were examined each morning for vaginal plugs. Under natural diurnal lighting mice generally ovulate and copulate about midnight; therefore, the ages of the embryos were recorded from the midnight before the vaginal plugs were found.

The tissues studied were 4-day blastocysts, uterine endometrium from mature virgin females in estrus and also from $41 / 2$-day pregnant mice, decidua from $91 / 2$-day pregnant mice, and the visceral yolk sac, chorio-allantoic placenta, and amnion dissected from embryos ranging from $9 \frac{1}{2}$ to 19 days postcoitum. These tissues were removed from the uteri under sterile conditions in physiological growth-medium No. 703 (Healy et al., '54), which was modified by the absence of glucose and antibiotics. The medium was also used for preparing embryo extract and for the nutrient medium of roller tube cultures. Another medium, the plasma-clot, containing equal volumes of plasma made from mouse blood withdrawn by ventricle puncture and of embryo extract prepared from $131 / 2$ - or $14 \frac{1}{2}$-day mouse embryos, was also used.

Pre-implantation blastocysts were flushed from uterine lumina of 4-day pregnant mice with growth-medium ejected from a hypodermic syringe through a 27 -gauge needle. The blastocysts were then washed thoroughly and incubated at $37^{\circ} \mathrm{C}$ in hanging-drop plasma-clots to which was added U-glucose-C-14 (Volk Radio-Chemical Co., Chicago; specific activity $1 \mathrm{mc} / 8.7 \mathrm{mg}$ of glucose) possessing 5-20 microcuries of radioactivity. The other tissues were isolated by dissection, 
teased into small tissue explants about one millimeter cubed, cultured in roller tubes containing $1 \mathrm{ml}$ of growth-medium No. 703 and 10 microcuries of U-glucose-C-14, and incubated in a roller drum at $37^{\circ} \mathrm{C}$. The patterns of cellular outgrowth, the changes in $\mathrm{pH}$ as indicated by phenol red, and the general appearance of the cultures were noted daily.

The cultures were prepared for paper chromatographic analyses following periods of metabolism which were thought sufficient to produce measurable quantities of labeled metabolites from U-glucose-C-14. The protein fractions were precipitated by $95 \%$ alcohol and removed by centrifugation. The supernatant fluids, alcoholic extracts containing the organic acids, were chromatographed without further preparation. The protein precipitates, however, were hydrolyzed before chromatography with $6 \mathrm{~N} \mathrm{HCl}$ in sealed vials under 15 pounds pressure at $120^{\circ} \mathrm{C}$ for 6 hours. Aliquots of both fractions were chromatographed on Whatman No. 1 paper using standard two-dimensional ascending chromatographic procedures (Block et al., '55). The first irrigating solvent for resolving the amino acids in the protein hydrolysates was phenol saturated with an aqueous buffer of $3.7 \% \quad \mathrm{KH}_{2} \mathrm{PO}_{4}$ and $6.3 \%$ sodium citrate at $\mathrm{pH} 5.9$; the second solvent contained 65 parts 2,6-lutidine and 35 parts distilled water (Berry et al., 51). The organic acids in the alcoholic extracts were resolved in the first direction by a 13:3:1 mixture of ether: acetic acid: water (Denison and Phares, '52) and in the second direction by the previously mentioned 2,6-lutidine solvent.

The radioactive areas on the chromatograms were located by placing sheets of No Screen Kodak Medical X-ray Film (manufactured by Eastman Kodak Company, Rochester, N.Y.) upon the chromatograms in casettes. After sufficient periods of exposure the films were developed and fixed. As illustrated in figures 1 and 2, the darkened areas on the developed films correspond to the areas which were exposed to the beta rays of C-14. After autoradiography the chromatograms were developed to locate the positions of various metabolites. The amino acids were identified by their specific color 
reactions with $0.2 \%$ ninhydrin in water saturated butanol and also by their characteristic $R_{\mathrm{f}}$ values (Berry et al., '51). The organic acids were identified by their specific color reactions with $0.1 \mathrm{~N}$ ammoniacal silver, fluorescense, and characteristic $R_{f}$ values (Buch et al., '52). The radioisotopically labeled metabolites on the chromatograms were then easily found with the aid of the autoradiograms since the positions of the radioisotopically labeled metabolites of each chromatogram correspond to the darkened areas on its autoradiogram (figs. 1 and 2).

Once the radioactive spots were delineated with the aid of the autoradiograms, then the radioactivity in each metabolite was assayed more accurately with a Geiger-Müller tube connected to a scaler. The total radioactivity on different chromatograms inevitably varied considerably and a meaningful comparison of different chromatograms could not be made directly; therefore, the radioactivity measurements on each chromatogram were converted into relative radioactivity as compared to the radioactivity of alanine on each chromatogram used as a standard. Thus the patterns of metabolism could be compared. (See Markert, '56 for further discussion of procedures).

\section{RESULTS}

The varied attempts in this investigation to culture mouse blastocysts deserve comment because many investigators have labored diligently without much success to grow blastocysts in vitro. Both culture media and various types of culture vessels were tested for their capacity to promote the growth of blastocysts. The most favorable arrangement tested was a small capillary tube filled with growth-medium and sealed at each end with melted paraffin. Mouse blastocysts did not manifest outward signs of cellular disintegration in this relatively anaerobic environment for extended periods of culture; however, when liberated from the capillary tubes they did exhibit greater fragility than freshly recovered blastocysts. It was also observed that blastocysts remained healthy for longer 


\section{PROLINE}

\section{ALANINE}

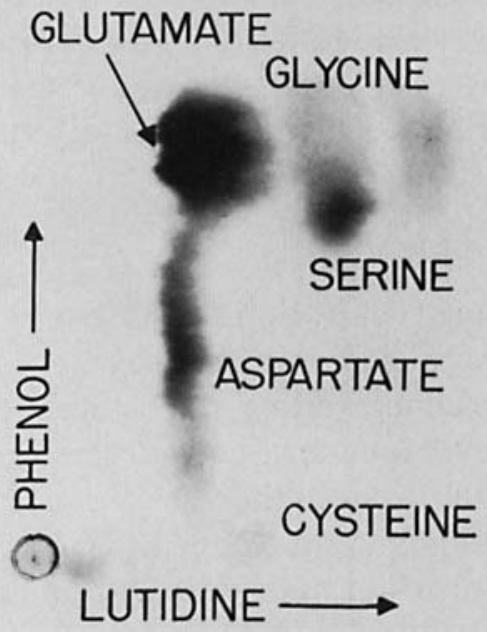

Fig. 1 Autoradiogram illustrating the amino acids produced by the 912-day visceral yolk sac from radioactively labeled glucose. In this culture $9 \frac{1}{2}$-day visceral yolk sae was incubated for 4 days in a hanging-drop plasma-clot containing 5 microcuries of uniformly labeled glucose-C-14. 


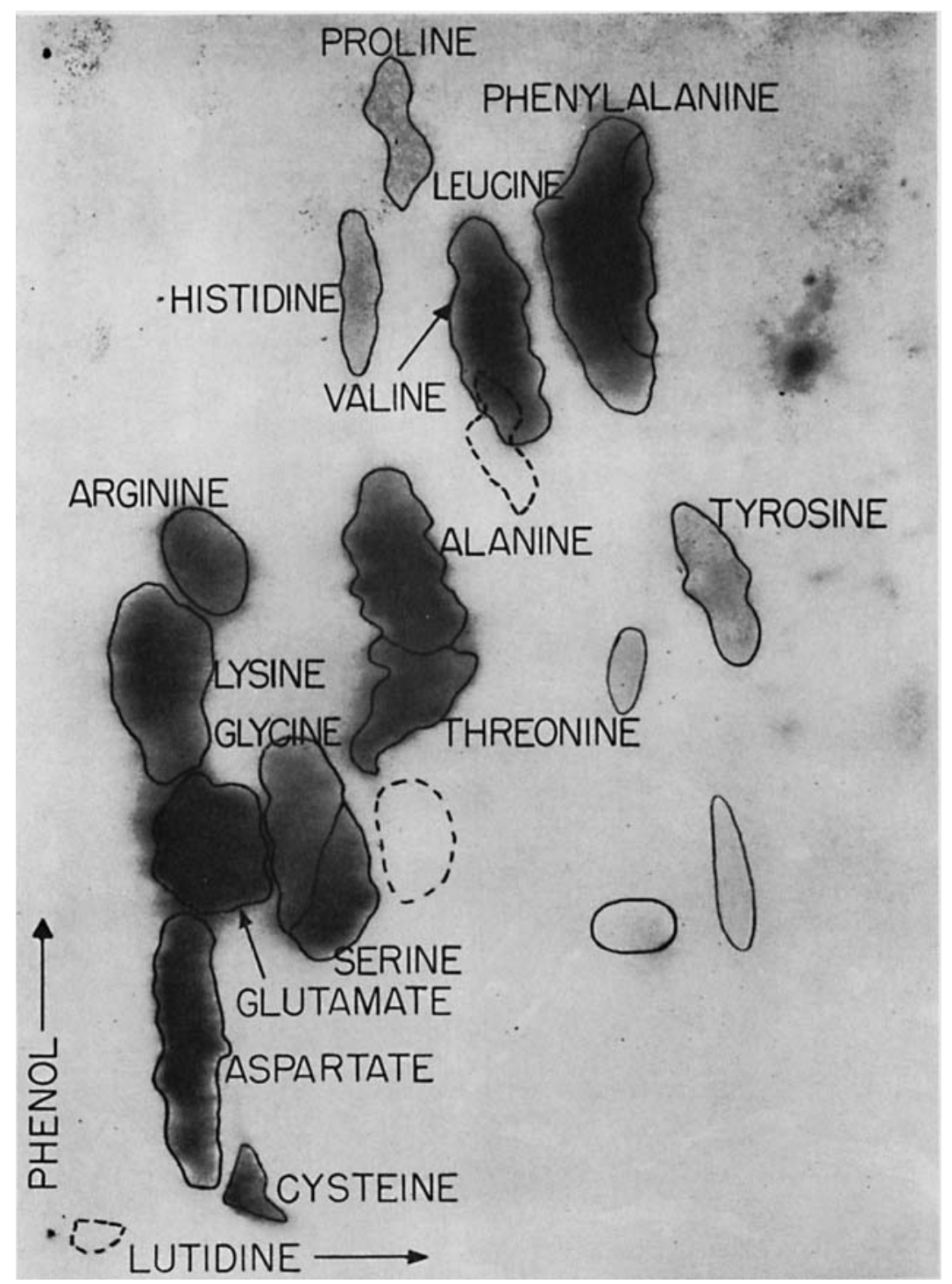

Fig. 2 Chromatogram illustrating the corresponding positions of the C-14 labeled amino acids, as well as the unlabeled amino acids, identified with ninhydrin. This is the chromatogram from which the autoradiogram in figure 1 was made. 


\section{LACTATE}

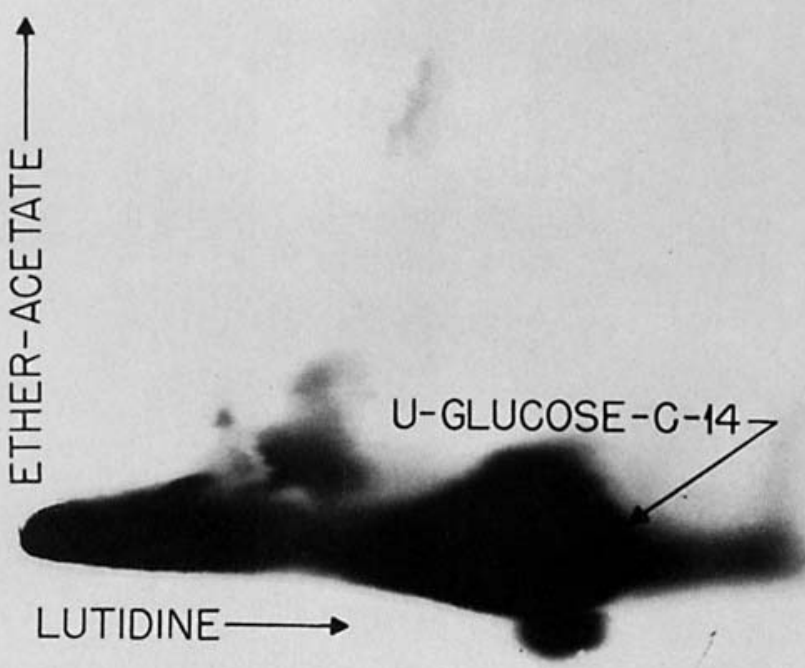

Fig. 3 Lactate synthesized by 4-day blastocysts from radioactively labeled glucose. In this culture 59 blastocysts were incubated for 22 days in a hangingdrop plasma-clot containing 20 microcuries of uniformly labeled glucose-C-14. 
periods of culture in plasma-clots than in synthetic media, indicating that the plasma-clot was either more nutritious or afforded better protection against hostile environmental factors. The failure of blastocysts to grow in capillary tubes filled with aqueous humor obtained from adult mouse eyes was somewhat surprising in view of the growth of blastocysts implanted into the anterior chamber of mouse eyes (Runner, '47). Media which were modified by the metabolic activity of small bits of uterine endometrium for 24 hours also failed to induce blastocyst growth.

Chromatographic analyses of uterine fluid removed at the time of blastocyst implantation and also at estrus revealed that several amino acids were present in concentrations similar to those of common synthetic growth-media, such as No. 703 (Healy et al., '54). Large quantities of taurine, a cysteine derivative, were also found in mouse uterine fluid. The synthetic media did not contain taurine, but it was present in the mouse plasma.

Observations of cultured blastocysts showed that older blastocysts remained healthy for longer periods of culture than did younger cleavage stages. Approximately $25 \%$ of the zonae pellucidae, which encapsulate the blastocysts at 4 days post-coitum, were dissolved during two weeks of culture in plasma-clots. Cell division in blastocysts in utero occurs approximately every 12 hours (Snell, '56) ; however, by mapping the cell membranes in the trophoblastic region of blastocysts immediately after culturing, it was found that no cell division occurred during 24 hours of in vitro culture. The inner-cell masses of a few blastocysts became enlarged forming egg-cylinder anlagen, but no mitotic figures were found in slightly squashed stained preparations of these blastocysts. Numerous surface blebs of trophoblastic origin developed on mouse blastocysts in plasma-clots. These bleds contained lipoid droplets and a watery fluid less viscous than the cytoplasm of freshly recovered blastocysts. Much of the cellular deuteroplasm was apparently metabolized, the normal semipermeability of the cell membranes subsequently disappeared, 
and then osmosis caused the trophoblast cells to swell and the blebs to form.

Analyses of cultured blastocysts metabolizing U-glucose-C14 demonstrated that mouse blastocysts converted glucose into several metabolites. These cultures always contained large quantities of labeled lactate (fig. 3 ). In 4 cultures containing $24,28,45$, and 59 blastocysts respectively, the quantities of

TABLE 1

Cellular outgrowth obtained from tissue explants

\begin{tabular}{|c|c|c|c|c|c|}
\hline TISsuns & $\begin{array}{c}\text { AGE OF } \\
\text { TISSVE } \\
\text { POST-COITUM }\end{array}$ & $\begin{array}{l}\text { RATE OF } \\
\text { METABO- } \\
\text { LISM } 1\end{array}$ & $\begin{array}{l}\text { FIBRO- } \\
\text { BLASTS } 2\end{array}$ & $\begin{array}{l}\text { MACRO- } \\
\text { PHAGES } 2\end{array}$ & $\begin{array}{c}\text { EPI- } \\
\text { THELTA }\end{array}$ \\
\hline Blastoeyst & 4 & low & 0 & 0 & 0 \\
\hline \multicolumn{6}{|l|}{ Uterine } \\
\hline endometrium & 0 & high & 0 & 1 & 3 \\
\hline \multicolumn{6}{|l|}{ Uterine } \\
\hline endometrium & $41 / 2$ & high & 0 & 1 & $\mathbf{3}$ \\
\hline Decidua & $91 / 2$ & high & 1 & 1 & 1 \\
\hline Placenta & $131 / 2$ & high & 3 & 2 & 1 \\
\hline Placenta & $181 / 2$ & high & 0 & 1 & 1 \\
\hline Amnion & $101 / 2$ & low & 1 & 1 & $\mathbf{0}$ \\
\hline Amnion & $13^{1 / 2}$ & moderate & 1 & $\begin{array}{lllll}1 & & & \end{array}$ & 0 \\
\hline Amnion & 19 & moderate & 1 & 1 & 0 \\
\hline \multicolumn{6}{|l|}{ Visceral } \\
\hline yolk sac & $91 / 2$ & moderate & 2 & 1 & 3 \\
\hline \multicolumn{6}{|l|}{ Visceral } \\
\hline yolk sac & $101 / 2$ & moderate & 2 & 2 & 3 \\
\hline \multicolumn{6}{|l|}{ Visceral } \\
\hline yolk sac & $131 / 2$ & high & 2 & 3 & 2 \\
\hline \multicolumn{6}{|l|}{ Visceral } \\
\hline yolk sac & $181 / 2$ & high & 1 & 2 & 3 \\
\hline
\end{tabular}

${ }^{1}$ Rates of metabolism are expressed as low, moderate, or high corresponding to the time required for each tissue to modify the $\mathrm{pH}$ of the medium from $\mathrm{pH} 7.6$ to $\mathrm{pH}$ 6.8, which was determined from the color of the phenol red indicator in the medium. A high rate indicates the change occurred within 24 hours of culture, a moderate rate signifies that two to 5 days of metabolism were necessary for this change, and a low rate means that the medium never became acidic during the period of culture.

2 The abundance of different cell types in the cellular outgrowth of tissue explants is expressed on a seale from $0-3$, where 0 indicates that no cells of this type were found, 1 means that relatively few cells were observed, 2 signifies that $10-30 \%$ of the cells were of this type, and 3 indicates that $50 \%$ or more of the cells were of this type. 


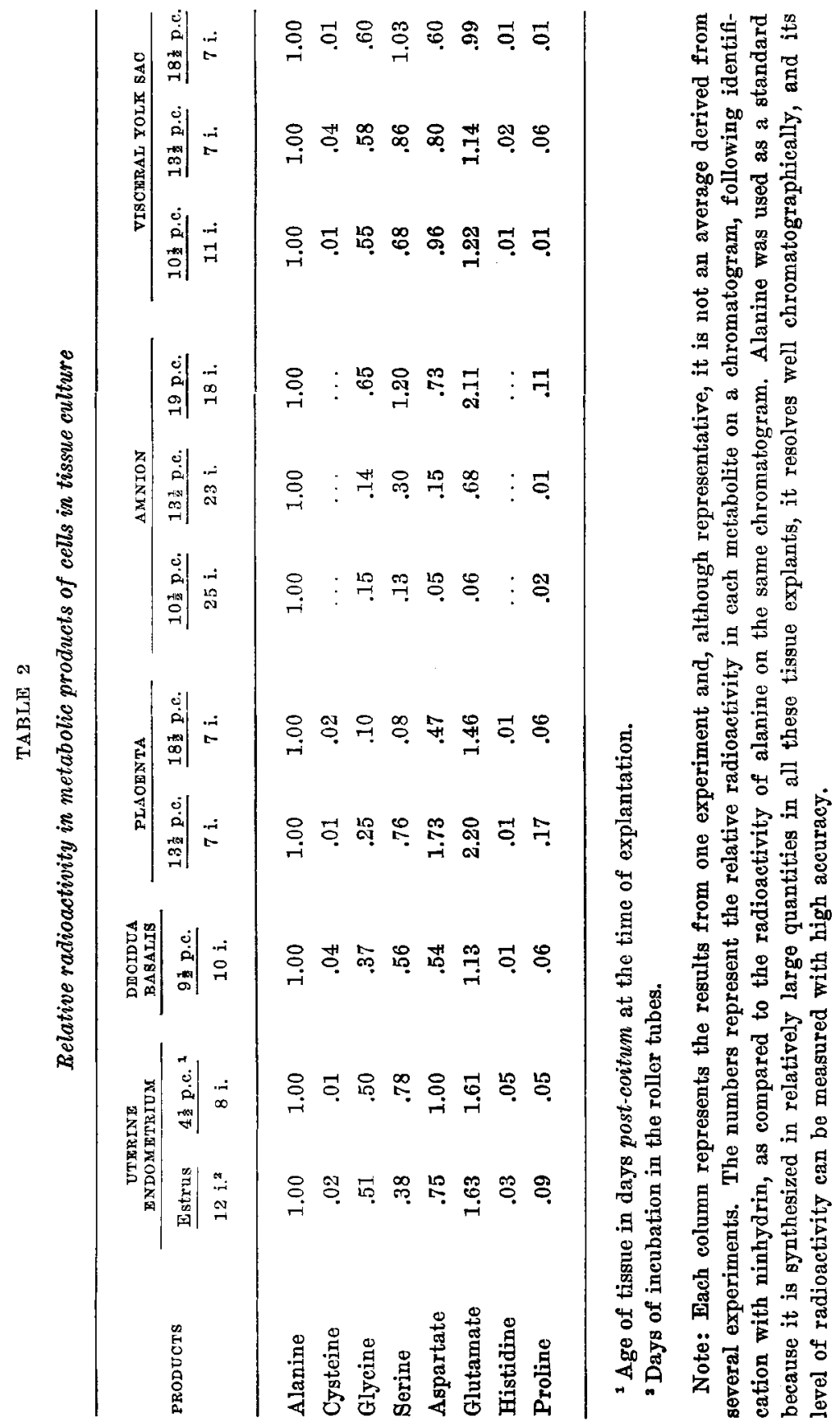


labeled lactate produced by metabolizing blastocysts were proportional to the number of blastocysts in each culture. Small quantities of alanine, glycine, and serine were also derived at least in part from U-glucose-C-14.

The patterns of cellular outgrowth and the relative rates of metabolism of the tissues explanted in roller tubes are presented in table 1. Analyses of the alcoholic extracts of these tissues showed that some residual U-glucose-C-14 and large quantities of radioisotopically labeled lactate were present in all the cultures. Detectable levels of radioactivity were usually present in pyruvate; however, long periods of autoradiography were required to detect the very low levels of radioactivity in the organic acid intermediates of the citric acid cycle since the concentration of these intermediates was very low, as indeed they are in most animal tissues. For this reason the levels of radioactivity in these organic acids were not analyzed statistically, as were the amino acids which arose from products of glycolysis or intermediates of the citric acid cycle. The relative radioactivity found in the amino acids of the various tissues is tabulated in table 2 . In general, the results of duplicated experiments varied less than plus or minus 10 per cent from those reported in table 2 .

\section{DISCUSSION}

Biochemical aspects. When cellular metabolism is studied in vitro the results must be interpreted with caution since the medium may change the normal activities of cells. Although cells in culture do not commonly acquire new metabolic capacities they frequently retain many of their initial capacities for extended periods of time, as has been shown by observations of established cell strains. For example, L strain mouse fibroblasts after 17 years of continuous in vitro culture have retained their capacity to produce fibers when placed in the proper culture conditions (Merchant and Kahn, '58). It may be assumed that the general pattern of metabolism of tissues freshly explanted to in vitro culture reflects the state 
of metabolism reached by the tissue at the time of explantation. To be sure, oxygen tensions, oxidation-reduction potentials, $\mathrm{pH}$, substrates, and other regulatory factors of in vivo systems are not faithfully reproduced in vitro; in spite of this, studies of cellular activities under specified conditions have been very helpful in elucidating normal metabolic activities.

Biochemical pathways of metabolism have already been determined for many metabolites and this information may be used in interpreting the data obtained in this investigation. The lactic acid produced by these tissues apparently arises from the anaerobic phosphorylation and breakdown of the 6-carbon chain of glucose into three-carbon units according to the generally accepted Embden-Meyerhof scheme of glycolysis ; however, the quantity of glucose metabolized through the hexose monophosphate shunt in these tissues is unknown. Some amino acids, alanine, cysteine, glycine, and serine, are synthesized principally from three-carbon units formed during anaerobic metabolism, whereas other amino acids, aspartate and glutamate, are generally synthesized from alpha-keto acids of the citric acid eycle, which is more active aerobically. Besides being an efficient means for synthesizing high energy phosphates, the citric acid cycle also provides a pool of precursors for carbohydrate, protein, and lipid metabolism. Two alpha-keto acids, oxalacetate and alpha-ketoglutarate, are the direct sources of two amino acids, aspartate and glutamate respectively, by transamination. Apparently proline and histidine also arise in part from products of the citric acid cycle since they are synthesized in proportionately larger quantities by tissues which metabolize principally aerobically.

It is important to recall that the citric acid cycle is a cyclic phenomenon and small quantities of these intermediates can keep the cycle functioning. Nevertheless, transamination of these intermediates for the synthesis of amino acids would create an excessive drain upon the system if the citric acid cycle constituents were not replenished. Ochoa and coworkers (' 48,50$)$ found that carbon dioxide fixation to pyruvate giving rise to malate occurs in the presence of triphospho- 
pyridine nucleotide ; more recently, Utter and Kurahashi ('54) have shown that oxalacetate can be synthesized from phosphoenolpyruvate and carbon dioxide. These reactions operate independently and either can effectively compensate for the alpha-keto acids removed from the citric acid cycle by transamination.

Nature of the in vivo growth-promoting factors. Some morphogenetic factors must be provided to stimulate growth in vivo since young mammalian embryos do not grow in vitro. Although the uterus provides an optimal environment for the embryos of its own species, it was found in this study that pieces of uterine endometrium, and also whole uteri containing blastocysts, failed to modify the medium and promote the morphogenesis of young embryos. Since the uterine endometrium in vitro does not synthesize the growth-promoting substances, they probably arise in extrauterine positions and should be transported through the circulatory system. Thus the blood of mice at the appropriate phase of pregnancy should contain them. The fact that implanted embryos must stimulate the development of an adequate vascular supply or they fail to grow and differentiate supports the idea that the blood contains some unique embryonic growth-promoting factors. Coelomic fluids alone are adequate for nurturing large volumes of ascitic cells, but these fluids will not support the growth of embryos. Moreover, blastocysts cultured in blood plasma from mice at several phases of pregnancy grew no better than those cultured in blood plasma from nonpregnant mice. It may be duduced, therefore, that growth-promoting factors occur generally in blood and are of small molecular size since they pass the blood-brain barrier and enter the aqueous humor; however, they must be unstable or in short supply since both the blood plasma and aqueous humor fail to promote blastocyst growth in vitro. The morphogenetic substances are doubtless not unique substances functioning only to promote embryonic growth since they are present in both males and females. It seems very possible that the conditions essential for embryonic growth are maintained in vivo by a dynamic 
metabolic equilibrium that would be very difficult to duplicate in vitro.

Observations that blastocysts maintain their integrity best in small, sealed capillary tubes under almost completely anaerobic conditions implies that aerobic environments are injurious to them. Although experimental data are not available, it can be deduced from what is generally known that the oxygen tension is low in sites where early embryos will implant and successfully develop, which suggests that the regulation of the oxidation-reduction potential may be very important in maintaining conditions favorable for the growth of young mammalian embryos. Previous attempts to regulate the oxidation-reduction potential of in vitro systems for the growth of blastocysts by the addition of glutathione (Pincus and Wertessen, '38) or methionine and cysteine (Miller and Reimann, '40) were not very rewarding. The simultaneous addition of glutathione and progesterone to culture media in this investigation also failed to promote the growth of mouse blastocysts. However, in view of more recent findings the role of the oxidation-reduction potential of anaerobic environments for promoting the growth of early mammalian embryos might profitably be investigated further.

Blastocyst metabolism. The results of U-glucose-C-14 metabolism indicate that mouse blastocysts respire anaerobically in vitro. This conclusion is based upon the facts that lactate is the principal end product of giucose metabolism and that the amino acids which generally arise from the citric acid cycle intermediates are not synthesized in detectable quantities in blastocyst cultures. It might be thought that one reason for the failure of blastocysts to grow in vitro results from their complete anaerobic metabolism. Indeed, this may be important but it is unlikely that it is the principal reason since the rate of cell division of some cells is not inhibited under complete anaerobiosis in vitro (Harris, '56). The metabolism of mouse blastocysts measured in these experiments is not that of rapidly growing embryos and probably more closely resembles the metabolism of mouse blastocysts. 
in a state of delayed implantation. It is possible that some aerobic respiration occurs in rapidly growing blastocysts. The zonae pellucidae disintegrate in slightly acid media (Hall, '35) and they may be dissolved in vitro by the increased acidity of the culture medium arising from lactic acid synthesis during culture.

The limited number of amino acids synthesized by the blastocysts per se illustrates their high degree of nutritional dependency. Chromatographic analyses show that mouse uterine fluid contains the required amino acids as well as other metabolites needed by blastocysts. Other evidence also suggests that the uterine endometrium supplies embryotrophe for unimplanted embryos. Osmiophilic substances in the epithelial cells of the endometrium are similar to the osmiophilic substances found in the trophoblastic cells of blastocysts (Bloch, '39; Alden, '47). Jenkinson ('02) also reported that trophoblastic cells could engulf red blood cells and presumably other substances present in the uterine lumen.

Endometrial metabolism. The results show that the uterine endometrium metabolizes both aerobically and anaerobically. The synthesis of large quantities of lactate demonstrates the occurrence of a high rate of anaerobic metabolism, whereas the production of aspartate, glutamate, and proline arising in part as transaminated products of the citric acid cycle indicates that the endometrium respires aerobically as well (table 2).

The in vitro metabolism of the endometrium shows that several of the amino acids in the uterine fluid are synthesized in situ. Although the uterine environment changes from the period of estrus through implantation (Chang, ' 51 ), it is not expressed in the pattern of amino acid synthesis from carbohydrates.

Decidual metabolism. The decidua arises from the uterine mucosa (Creighton, 1878), completely encapsulates the embryo, and can readily release stored nutrients for the developing' embryo (Wislocki et al., '46). The metabolic similarity of the decidua and uterine endometrium in providing nutrients 
for the developing embryo is borne out by their similar patterns of metabolism (table 2 ).

Placental metabolism. The maternal portion of the discoidal placenta arises directly from the decidua basalis. Fetal chorio-allantoic vessels invade the decidua basalis and bathe in the blood lacunae connected with maternal uterine blood vessels. The outgrowth of giant fibroblasts arising from the placenta explants removed during this period of vascular invasion (table 1) expresses an in vivo property of the fetal placenta at this time.

The changing patterns of metabolism reflect the developmental and physiological changes occurring in the placenta. The relative increase in aspartate, glutamate, proline, and histidine synthesis shows that the placenta possesses a favorable site for aerobic respiration; however, being embryonic tissue it still demonstrates a relatively high rate of anaerobic respiration (Bell et al., '28). It is also evident that just before parturition the placenta acquires a more anaerobic pattern of metabolism (table 2).

Table 2 shows that the placenta could convert large amounts of glucose absorbed from the maternal circulation into amino acids which could then be made available to the fetus directly; however, presently there is little evidence that this actually occurs in the mammalian placenta. Although proteases have been found in all placentae examined, no one has shown that they are involved in the hydrolysis or synthesis of embryonic proteins. Christensen and Streicher ('48) have shown, however, that the guinea pig placenta concentrates by 4 to 6 fold some of the amino acids absorbed from the maternal blood.

Amnion metabolism. Recent studies by Flexner and Gellhorn ('42) and Vosburg et al., ('47) on the rate of turnover of water and salts in amniotic fluid have placed a new emphasis upon the role of the amnion in embryonic development. It is now known that the amniotic fluid is not a stagnant pool. The amniotic fluid is not strictly a fetal product and it probably arises from amnion cells since amniotic fluid is produced in many cases even if the embryo does not develop. 
The nonvascular amnion might be expected a priori to respire anaerobically in vitro. Its increased capacity to synthesize glutamate and aspartate with increased embryonic age implies that an elevated aerobic activity occurs in this tissue during later fetal life (table 2). The disintegration of the decidua capsularis, parietal wall of the yolk sac, and Reichert's membrane during the later stages of gestation may enchance the diffusion of dissolved oxygen from the uterus into the embryonic exocoelom.

Visceral yolk sac metabolism. Although the yolk sac is vestigial in most animals with a highly developed allantoic placenta, the mouse is an exception. Moreover, this study on the growth and metabolism of pieces of yolk sac in vitro shows that the visceral yolk sac of the mouse remains functional throughout gestation (table 2). The size and phylogenetic relationship of the rodent yolk sac compared with those of primitive mammals suggests that it functions as a placenta during early pregnancy. It accumulates large quantities of glycogen and lipids which may be utilized to nurture the embryo. The absorption of dyes (Wislocki et al., '46) and agglutinins (Brambell, '54) suggests that the endodermal cells of the visceral yolk sac have placental activities. The cytological details of the apical ends of these endodermal cells have been studied with the electron microscope and the presence of villiform processes and cryptiform invaginations communicating with a canalicular system indicates that pinocytosis occurs in these colls (Dempsey, '53).

This in vitro study clearly indicates that the visceral yolk sac synthesizes many nutrients which can be transported to the developing embryo via the vitelline circulation (fig. 4). Thus, the visceral yolk sac not only absorbs nutrients but it also synthesizes de novo many nutrients which are utilized by the developing embryo.

The number of macrophages in the cellular outgrowth of the visceral yolk sac cultured at various stages of development is correlated with its hematopoietic activity. The greatest number of macrophages, possible blood forming cells, are observed 


\section{PROLINE}

\section{ALANINE}

\section{GLUTAMATE}

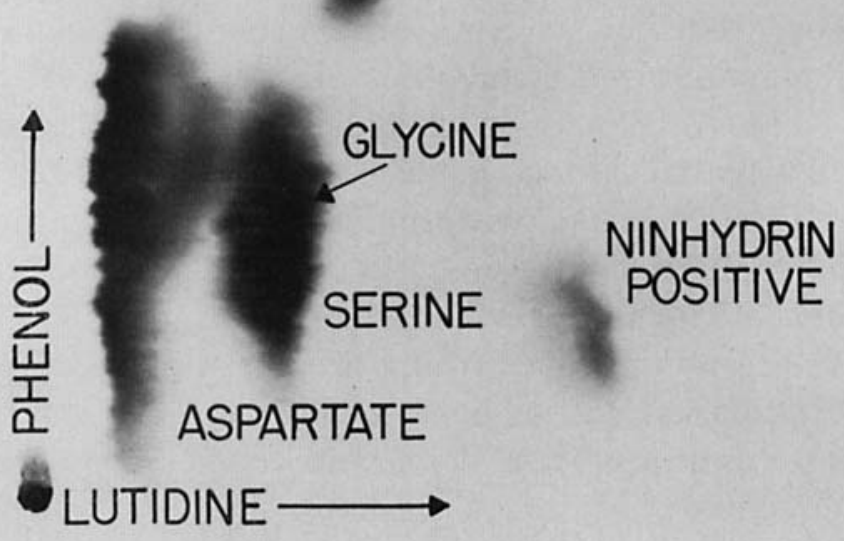

Fig. 4 Labeled amino acids derived from radioactively labeled glucose by $13 \frac{1}{2}$-day visceral yolk sac. Roller tubc culture ineubated for 10 days in $1 \mathrm{ml}$ of physiological growth-medium No. 703 containing 10 microcuries of uniformly labeled glucose-C-14. 
in cultures of visceral yolk sac ranging from the eleventh day of gestation until the day before parturition (table 1), which is also the period of hematopoiesis in the visceral yolk sac.

\section{SUMMARY}

1. The objectives of this investigation were to study various aspects of the growth and metabolism of young embryos, extraembryonic membranes, and the uterine endometrium of the mouse. From the results of these studies it was possible to postulate certain interdependent and interrelated metabolic activities of embryonic significance in these tissues.

2. The tissues were cultured in vitro and their metabolic activities were analyzed by the use of C-14-labeled compounds coupled with chromatographic and autoradiographic techniques.

3. Mouse blastocysts in vitro synthesized large quantities of lactate and lesser amounts of alanine, glycine, and serine from C-14-labeled glucose; however, mouse blastocysts did not synthesize aspartic or glutamic acids. Thus, it was deduced that mouse blastocysts metabolize principally anaerobically since the synthesized metabolites are generally derived from intermediates of glycolysis, whereas aspartate and glumate are gencrally synthesized from intermediates of the citric acid cycle, which is more active aerobically. It was also found that aerobic environments were less favorable than anaerobic environments for the growth of young embryos.

4. The results obtained from culturing the fastidious mouse blastocysts in various media and culture vessels were used as a basis for a discussion of the nature of the unknown morphogenetic factors which are essential for blastocyst development - possibly these conditions are maintained in vivo by a delicate dynamic equilibrium not yet duplicated in vitro.

5. The extraembryonic tissues in vitro produced variable amounts of several amino acids which are utilized by the embryo in protein synthesis. Thus these tissues may have nutritional as well as mechanical roles during embryogeny. 
6. The data also showed that the visceral yolk sac of the mouse remains metabolically functional throughout gestation and does not become physiologically vestigial following the development of the chorio-allantoic circulation.

\section{LITERATURE CITED}

ALDEN, R. H. 1947 Implantation of the rat egg. II. Alteration in osmiophilie epithelial lipids of the rat uterus under normal and experimental conditions. Anat. Rec., 97: 1-28.

Beld, W. B., L. Cunningham, M. JowetT, H. Mituett and J. Brooks 1928 The metabolism and acidity of the foetal tissues and fluids. Brit. Med. J., 1: $126-131$.

Berry, H. K., H. E. Sutron, L. CaIN aNd J. S. Berry 1951 Development of paper chromatography for use in the study of metabolic patterns. Biochem. Inst. Studies IV. Univ. of Texas Pub., 5109 : 22-55.

BitTner, J. J., AND C. C. LITrte 1937 Transmission of breast and lung cancer in mice. J. Hered., 28: 117-121.

BLoCH, S. 1939 Contributions to research on the female sex-hormones; implantation of the mouse egg. J. Endocrin., 1: 399-408.

Block, R. J., E. T. DURRUM AND G. ZWeitg 1955 A Manual of Paper Chromatography and Paper Electrophoresis. Academic Press, Inc., New York.

Brameli, F. W. R. 1954 Transport of proteins across the fetal membranes. Cold Spring Harbor Symposia on Quant. Biol., 19: 71-81.

Briones, H., aNd R. A. Beatty 1954 Interspeeific transfers of rodent eggs. J. Exp. Zool., 125: 99-118.

Buch, M. L., R. Montgomery and W. L. Porter 1952 On paper chromatography of organic acids. Anal. Chem., 24: 489-491.

Chang, M. C. 1951 Fertility and sterility as revealed in the study of fertilization and development of rabbit eggs. Fert. and Steril., 2 : 205-222.

Christensen, H. N., and J. A. Streicher 1948 Association between rapid growth and elevated cell concentrations of amino acids. I. In fetal tissues. J. Biol. Chem., $175: 95-100$.

CREIGHTON, C. 1878 The formation of the placenta in the guinea pig. J. Anat. and Physiol., 12: 534-590.

DEMPSEY, E. W. 1953 Electron microscopy of the visceral yolk-sac epithelium of the guinea pig. Am. J. Anat., 93: 331-363.

Denison, F. W., JR., ANd E. F. Phares 1952 Rapid method for paper chromatography of organic acids. Anal. Chem., 24: 1628-1629.

FawcetT, D. W., G. B. Wrstooki and C. M. WaLdo 1947 The development of the mouse ova in the anterior chamber of the eye and in the abdominal cavity. Am. J. Anat., 81: 413-444.

Flexner, L. B., and A. Gellhorn 1942 The transfer of water and sodium to the amniotic fluid of the guinea pig. Am. J. Physiol., 136: 757-761. 
GLURCKSOHN-Schonangimer, S. 1941 Development of early mouse embryos in the extraembryonic coelom of the chick. Science, 93: 502-503.

1944 The development of normal and homozygous brachy (T/T) mouse embryos in the extraembryonic coelom of the chick. Proc. Nat. Acad. Sci., 30: 134-140.

GRoBsTeIN, C. 1950 Production of intra-ocular hemorrhage by mouse trophoblast. J. Exp. Zool., 114: 359-376.

HALL, B. V. 1935 The reactions of rat and mouse eggs to hydrogen ions. Proc. Soe. Exp. Biol. Med., 32: 747-748.

HARRIS, H. 1956 The relationship between the respiration and multiplication of rat connective tissue cells in vitro. Brit. J. Exp. Path., 37: 512-517.

Healy, G. M., D. C. Fisher and R. C. Parker 1954 Nutrition of animal cells in tissue culture. IX. Synthetic medium No. 703. Canad. J. Biochem. Physiol., 32: 327-337.

HEAPE, W. 1890 Preliminary note on the transplantation and growth of mammalian ova within a uterine foster-mother. Proc. Roy. Soc. (Lond.), 48: 457-458.

JENKINSON, J. W. 1902 Observations on the histology and physiology of the placenta of the mouse. (From F. H. A. Marshall 1952 Physiology of Reproduction. Vol. II. Longmans, Green and Co., London, England).

MARKERT, C. L. 1956 The ontogeny of divergent metabolic patterns in cells of identical genotype. Cold spring Harbor Symposia on Quant. Biol., 21: $339-348$.

Maximow, A. A. 1923 In vitro cultures of mammalian embryos. Anat. Ree, 25: 141-142.

1925 Tissue culture of young mammalian embryos. Contr. Embryol. Carneg. Instn., 16: 47-114.

MERChant, D. J., AND R. H. KAHN 1958 Fiber formation in suspension eultures of L strain fibroblasts. Proc. Soc. Exp. Biol. Med., 97: 359-362.

MILIER, B. J., AND S. P. REIMANN 1940 Effect of DL-methionine and L-cysteine on the cleavage rate of mammalian eggs. Arch. Path., 29: 181-188.

NichoLas, J. S. 1933 Development of transplanted rat eggs. Proc. Soc. Exp. Biol. Med., 30: 1111-1113.

1942 Experiments on developing rats. IV. The growth and differentiation of eggs and egg-eylinders when transplanted under the kidney capsule. J. Exp. Zool., 90: 41-71.

Nicholas, J. S., AND D. RUDNick 1933 The development of embryonic rat tissues upon chick chorioallantois. Ibid., 66: 193-256.

1938 Development of rat embryos of egg-cylinder to head-fold in plasma cultures. Ibid., 78: 205-232.

OCHOA, S., A. H. MEHLER AND A. KoRNBERG 1948 Biosynthesis of dicarboxylic acids by earbon dioxide fixation. I. Isolation and properties of an enzyme from pigeon liver catalyzing the reversible oxidation decarboxylation of L-malic acid. J. Biol. Chem., 174: 979-1000.

Pincus, G., and N. T. Werthessen 1938 The comparative behavior of mammalian eggs in vivo and in vitro. III. Factors controlling the growth of the rabbit blastocyst. J. Exp. Zool., 78: 1-18. 
RUNNGR, M. N. 1947 Development of mouse eggs in the anterior chamber of the eye. Anat. Rec., $98: 1-18$.

SNHLL, G. D. 1956 Biology of the Laboratory Mouse. Dover Publications, Inc., New York.

UTrer, M. F., AND K. KURAHAshI 1954 Mechanism of action of oxalacetic carboxylase. J. Biol. Chem., 207: 821-841.

Verga SALLes, J. B., AND S. OChOA 1950 Biosynthesis of dicarboxylic acids by carbon dioxide fixation. II. Further study of the properties of the "malic"' enzyme of pigeon liver. Ibid., 187: 849-861.

Vosburgh, G. J., D. B. Cowir, L. M. Hellman, W. S. WILde aNd L. B. Flexner 1947 The rate of renewal in man of the water and sodium of the amniotic fluid as determined by tracer techniques. Anat. Ree., $97: 408$.

WhiтteN, W. K. 1956 Culture of tubal mouse ova. Nature, 177: 96.

Wislockt, G. B., H. W. Deane AND E. W. Dempsey 1946 The histochemistry of the rodent's placenta. Am. J. Anat., 78: 281-345. 